\title{
VALDOMIRO SILVEIRA E AFONSO ARINOS - ENCONTRANDO A VOZ DO SERTÃO
}

\author{
Gustavo Krieger Vazquez \\ Mestrando em Letras pela Universidade Federal do Paraná (UFPR) \\ kriegervazquez@hotmail.com
}

\section{RESUMO}

Desde os primórdios do regionalismo, seus autores buscaram retratar, através de maneiras diversas, as elusivas vozes do sertão. No fim do século XIX e início do século XX, dois autores, Afonso Arinos e Valdomiro Silveira, utilizaram, no discurso de suas personagens, mais de uma forma discursiva: a norma culta, uma narração híbrida - em que narrador e personagens mantêm o mesmo nível dialetal - e uma transcrição ortográfica, formas essas que, nos anos subsequentes, encontraram fruição sob a pena de outros autores. Iremos estudar contos desses dois escritores, lançando questões sobre a afirmação feita por Antonio Candido, em "A literatura e a formação do homem", de que a forma discursiva pode indicar um sentimento de superioridade do escritor para com o homem retratado.

Palavras-chave: regionalismo, discurso, Afonso Arinos, Valdomiro Silveira.

\section{ABSTRACT}

Since the early days of regionalism, its writers sought to portray, in different ways, the elusive voices of the hinterland. In the late 19th century and early 20th century, two authors, Afonso Arinos and Valdomiro Silveira, used in their tales more than one discursive form: the cultured norm, a hybrid narration - in which narrator and characters maintain the same dialectal level - and an orthographic transcription, forms that, in the following years, found fruition with other authors. We will study some short stories by both writers, raising questions about the statement made by Antonio Candido, in "Literature and the Formation of Man", that the discursive form may indicate a feeling of superiority of the writer over the portrayed man.

Keywords: regionalism, narration, Afonso Arinos, Valdomiro Silveira. 


\section{Introdução}

Em seu clássico texto "A literatura e a formação do homem", Antonio Candido afirma que o regionalismo, ao retratar uma parcela da população brasileira, pode ter uma função social tanto alienadora quanto humanizadora, "conforme o aspecto ou o autor considerado" (CANDIDO, 2002, p. 86). De acordo com o crítico, visto que o estilo gera atrito ao buscar unir o tema rústico de histórias vividas por personagens incultas e as formas cultas da literatura, o modo como o autor lida com esses elementos pode ter um caráter positivo ou negativo para o entendimento que um país tem de si mesmo.

Para exemplificar, Candido mostra dois casos distintos: de um lado, o conto "Mandoví", de Coelho Neto, em que o narrador mantém a voz culta, enquanto as personagens falam em um dialeto feito a partir da transcrição ortográficai; de outro, "Contrabandista", de Contos gauchescos (1912), de Simões Lopes Neto, em que há uma forma híbrida, um amálgama entre o discurso do narrador e o das personagens. Para o crítico, a primeira opção representaria elitismo e soberba por parte do autor, enquanto a segunda seria uma forma mais justa e complexa de retratar o homem sertanejo.

Candido (2002, p. 87) comenta então que ambos os estilos estão presentes em todas as fases do regionalismo, e muitas vezes em obras diversas do mesmo autor. Mas não nos é dado nenhum exemplo disso. De fato, a forma do discurso das personagens na literatura regionalista não foi estudada por Candido a fundo, em nenhum outro de seus variados artigos que tratam do gênero.

Acreditamos, porém, que essa busca por uma forma de mostrar o discurso das personagens é parte fundamental do continuum pela qual o regionalismo passou desde seus primórdios, quando apenas a norma culta era utilizada (Alencar, Bernardo 
Guimarães, Távora, etc.), até a geração de 30 e adiante, quando essas formas discursivas já estavam assentadas em nossa literatura - graças, sem dúvida, a esses autores anteriores, que as experimentaram.

Nosso intuito é mostrar as primeiras dessas experiências, ao mesmo tempo em que exemplificamos a afirmação de Candido - a de que mais de uma forma foi buscada pelo mesmo autor. Faremos isso com contos de dois pioneiros, Valdomiro Silveira e Afonso Arinos, que escreveram utilizando não apenas a transcrição ortográfica e a forma híbrida, mas também têm contos escritos somente em norma culta.

Mostrando as tentativas de cada um, desejamos suscitar algumas questões a respeito dessas escolhas discursivas, o que acreditamos estar acima de uma negatividade ou positividade, uma justiça ou soberba para com o ser humano retratado, mas que define, acima de tudo, uma busca pelo inexplorado.

\section{0 discurso das personagens sertanejas}

A verossimilhança que um autor regionalista busca ao escrever sua obra envolve inúmeras questões. O trabalho precisa ser não apenas coerente, mas também crível histórica e geograficamente, nas relações e estruturas sociais, na arquitetura rural, nas descrições de animais domesticados e selvagens, etc. De grande importância entre todas as particularidades da literatura regionalista é a questão do discurso das personagens.

Observando os primeiros regionalistas - Taunay, Távora, Guimarães, Alencar poderíamos afirmar que a opção tomada por eles para retratar o linguajar do sertão foi a

mais segura: as personagens falam segundo a norma culta. Além de facilitar o entendimento do leitor, é compreensível que, diante das inúmeras novidades que o 
interior apresentava, a linguagem coloquial pareceria um excesso. Já havia paisagens físicas grandiosas e material humano distinto para que o elemento particular da fala encontrasse espaço.

Essa opção é explicada em uma advertência escrita por Taunay, como prólogo de seu conto "Juca, o tropeiro" (1874), sendo a história o relato de algo que teria sido ouvido de um ex-sargento:

O que fizemos foi desbastar o correr da história de incidentes por demais longos, de inúmeros termos familiares, e sobretudo de locuções chulas e sertanejas que podiam por vezes parecer inconvenientes. Havendo contudo reconhecido a originalidade e força de colorido dessa linguagem, e desejando conservar ainda um quê da ingênua, mas pitoresca expressão do narrador, resultou uma coisa esquisita, nem como era quando contada pelo ex-sargento, nem como deveria ser, saída da mão de quem se atira a escrever para o público.

Batemos de arrependido nos peitos (TAUNAY, 2014, p. 287).

Se existe a preocupação com os leitores, também há o julgamento do autor em relação a locuções "inconvenientes" e, inclusive, a opinião sobre a ingenuidade do coloquialismo, o que faz o arrependimento final soar um tanto irônico. No conto, a norma culta é utilizada tanto na narração quanto nos diálogos, exceto um ou outro "vancê" ou "vassuncê" espalhado ao longo do texto.

Explicando tal escolha, Fernando Gil nos aponta sobre a época:

Nesse momento, somente a linguagem culta e citadina poderia dar reputabilidade ao mundo rural configurado literariamente, pois este somente poderia ser reconhecido como extensão do mundo dos homens letrados, como "coisa" a lhe pertencer e a que esses homens dariam voz (GIL, 2016, p. 30). 
Essa escolha permaneceu presente ao longo da história literária; sempre existiram autores regionalistas que utilizaram o mínimo ou mesmo nenhum traço de dialeto, seja um Távora, com O cabeleira, no século XIX, ou um Ronaldo Correia de Brito, com Faca, do século XXI.

É fato que a linguagem do sertão é volúvel, maleável, inconstante. Não há um léxico fixo, uma gramática definida: o falar do sertão não é controlável. É algo em que o caos está presente assertivamente, e nossos escritores precisaram, de alguma maneira, domar esse caos. Manter a norma culta foi uma opção, mas, com o passar do tempo, certos autores buscaram soluções diferentes para isso.

Além da norma culta, tanto para narrador quanto para personagens, na literatura brasileira houve autores que distanciaram os níveis de discurso, mantendo uma linguagem culta para o narrador e uma coloquial para as personagens; e também os casos em que mantiveram a linguagem coloquial. Veremos dois autores que utilizaram todas essas formas.

\section{Afonso Arinos}

Apesar da obra de Arinos ser quantitativamente breve, sua busca por formas diversas para retratar o interior do país já bastaria para o colocarmos em um rol de grande importância. Observemos suas tentativas com técnicas diversas para alcançar a voz do sertão.

Sua obra mais importante é o livro de contos Pelo Sertão, de 1898. Nele, o autor utiliza a norma culta para as personagens com frequência. Por exemplo, no conto "Pedro barqueiro", o próprio Pedro, criminoso em fuga, não se esquece da gramática nem em 
momentos de grande tensão: "Pede perdão, cabrito desavergonhado, do que fizeste ontem, que te vou mandar para o inferno!" (ARINOS, 2006, p. 147).

Se observarmos a resposta do escritor ao crítico Joaquim Alves, que julgava o conto "Esteireira" como sendo inverossímil por causa das situações apresentadas, notamos como o sertão poderia causar estranhamento no público leitor. Em sua defesa, Arinos aponta que um homem da cidade não teria um molde para o "animal humano destas Gerais, bravio, crescido às grosseiras carícias dos ventos da Chapada [...]" (ARINOS, 2014, p. 321). Em suas escolhas criativas, podemos supor que Arinos, para ser lido, decidiu eliminar, na maior parte das vezes, essa outra estranheza, a da fala coloquial.

Mas mesmo em Pelo sertão encontramos algo diferente: no conto "Joaquim Mironga (tipo do sertão)" há três níveis discursivos que se alternam: um narrador culto ouve uma história vivida e contada por Joaquim Mironga, que narra sua história com dialeto - história essa que contém dentro de si discursos de outras personagens, também em dialeto. A alteração de vozes pode ser vista logo no início do conto:

- O sol estava querendo sumir, quando eu encostei a porteira. Pulei da sela e amarrei, no moirão, o ruço pedrês - bicho malcriado, reparador, mas de espírito. No lombo desse pagão eu comia doze léguas, de uma assentada. Olhei a frente da casa, pus a mira no alpendre e não vi ninguém. - Uai, Joaquim, aí tem coisa! - Entrei bem sutil, reparando duma banda e outra.

Patrão velho, na hora em que eu estava arreando o pedrês, tinha chegado perto de mim, dizendo: - Olha lá, Mironga, não me vás sair um perrengue!

- Perrengando, perrengando, meu branco, eu entrei lá dentro. Vossemecê há de ver, com o favor de Deus."

- Olha o café, Joaquim, sem te cortar a conversa - disse um caboclo meão, de chapéu de couro e sisigola. E estendeu o coité fumarento, onde parecia ainda borbulhar o líquido.

$\mathrm{Na}$ varanda da frente, a gente do retiro estava reunida para ouvir o Joaquim (ARINOS, 2006, p. 117-118). 
Em 1921, cinco anos após o falecimento do autor, seus contos esparsos foram reunidos em um livro intitulado Histórias e paisagens. Não nos é claro o propósito que Arinos poderia ter com eles - se estava planejando um livro maior ou se esses contos seriam sobras da sua vida anterior à política e que foram reunidos por alguém. Se em alguns contos ele mantém a norma culta em todos os níveis (por exemplo, em um diálogo de "Menestrel do sertão", o sertanejo diz: "Que venha um candeeiro, dona, que está ficando meio escuro e eu tenho alguma coisa a pedir-Ihe" (ARINOS, 2006, p. 174)), em "A garupa" encontramos diálogos coloquiais com uma transcrição mais fiel ao linguajar sertanejo, sem porém serem transcrições ortográficas.

No conto, dois vaqueiros estão viajando, quando um deles falece inesperadamente. Cabe ao sobrevivente amarrar o cadáver às costas e levá-lo para um enterro digno. Nas conversas, observamos coloquialismo, sem que com isso se perca demais do português culto ou que fique "esquisito", como temia Taunay:

- Qual compadre! Vamos juntos. Assim como assim, a gente não pode chegar à casa hoje. Pois então, a gente viajeia junto, e da Água Limpa eu torço lá para Fundão, para pegar as novilhas; vancê apanha lá adiante o caminho do logradouro.

Eu já ia indo um pedaço, quando dei de rédeas para trás e ajuntei-me outra vez com o compadre. Parece que ele estava adivinhando! (ARINOS, 2006, p. 152-153).

Essa forma híbrida de transcrever o linguajar do sertão busca adicionar à língua culta palavras e expressões próprias do interior, mas sem deformá-la o suficiente para perder as normas gramaticais (pelo menos não todas), nem se aproximar de uma transcrição ortográfica; também importante, as personagens mantêm o mesmo nível discursivo do narrador. 
Como exemplificado por Candido, através da obra de Coelho Neto, outra opção utilizada por escritores para o retratamento do sertão foi transcrever as falas de seus habitantes "de ouvido", aproximando rigorosamente as palavras no papel do som pronunciado. Isso foi um modo que Arinos também experimentou. Observamos isso em outro conto de Histórias e paisagens: "O mão-pelada". Nele, dois negros conversam sobre a experiência de um deles ao ver, durante sua infância, a criatura referida no título. Aqui, Arinos busca retratar a falta de domínio linguístico das personagens, visto o português não ser, para eles, a língua materna. Em determinado momento, Quindanda fala: "lô tá lemblado também do que ocê tá pensano. Cruz, Ave-Malia! Nossinhô do céu me livre do mão-peluda!". O narrador, enquanto isso, segue a norma culta; logo em seguida, sobre a

outra personagem, João Congo, ele escreve: "Pouco a pouco, às golfadas, começou a desabafar-se, recontando, hora em língua da Costa, ora em sua meia-língua portuguesa, a história terrível" (ARINOS, 2006, p. 198).

O falecimento inesperado de Arinos, em 1916, nos impediu de saber o que ele buscava, e só nos resta conjecturar como seriam suas obras posteriores.

\section{Valdomiro Silveira}

Um autor que divide com Arinos a primazia do conto regionalista é Valdomiro Silveira. Ambos começaram a publicar suas histórias em 1894, em jornaisii. Silveira, muito provavelmente, foi o primeiro autor de nosso país a se concentrar exclusivamente no povo do sertão - todos que o precederam possuem uma ou mais obras situadas em ambiente urbano. 
Silveira escreveu no início de sua carreira alguns contos regionalistas seguindo a norma culta, como era comum até então (FREDERICO, 2007, p. xi-xii). São obras que o autor viria a renegar, mantendo desde então uma busca por trazer à página as maneiras próprias de falar do homem do interior.

As histórias de seu primeiro livro, Os caboclos, publicado em 1920, tratam de questões do dia a dia dos sertanejos. Romances, problemas de casamento, disputas por terras, o trato com os animais, doenças: temos um mundo hermético onde mesmo coadjuvantes não caipiras são raros. Esses contos foram escritos e publicados entre 1897 e 1906 em jornais diversos - com exceção de um, "Desespero de amor", de 1915. Mantendo ele a mesma estrutura e estilo dos outros contos, será aquele que iremos estudar.

O enredo é simples: Chico Só, vaqueiro, e nh'Ana, uma menina mimada, se apaixonam e se casam. Anos depois, um amigo de Chico comenta que a esposa deste o está traindo; com a raiva que passa a sentir após ouvir esse aviso, o vaqueiro empurra o amigo por um barranco, deixando-o para trás - "só não lembrou de que talvez estivesse a correr perigo de vida quem por ele, mundo afora, mais de uma vez expusera a sua" (SILVEIRA, 1962, p. 135). Voltando para sua casa, Chico fica de tocaia. Lá, ele vê uma mulher mal-falada:

E a voz da Balancia falou cautelosamente para a sala de jantar, como uma voz que sabe bem a viagem que tem de fazer:

- Nh'Ana, você não quer que leve hoje argum recado p'r'o Berto? (SILVEIRA, 1962, p. 136).

O conto possui certa riqueza, pela ambiguidade, deixando no ar os desfechos dos eventos, como indicam as citações prévias: não sabemos se o amigo do protagonista 
morreu ou se havia de fato uma traição - Berto seria o suposto amante de nh'Ana. No mais, como em outros contos de Os caboclos, a linguagem do narrador é erudita "entretanto, se lhe notavam de desatinados semelhantes exageros, por uma moça que, no fim de contas, ia ser tão pobre como as outras, ele respondia com todo o gás [...]" enquanto as personagens falam com um dialeto que vai da transcrição ortográfica "Home', eu não tenho mesmo quaje nada. Mas porém pissuo este meu sanguinho, a nh'Ana [...]" - ao erudito, inclusive na mesma frase - "[...] a nh'Ana, que é a maior riqueza do mundo: já vê que hei de tratar com todo o carinho a riqueza única que eu tenho, pois não é?" (SILVEIRA, 1962, p. 131).

Como em toda transcrição ortográfica, observamos a necessidade do autor em manter algo legível. Muitas vezes as palavras escolhidas para serem transcritas coloquialmente são aquelas que o leitor consegue facilmente compreender, enquanto outras palavras que um homem do sertão dificilmente pronunciaria corretamente - sem contar a gramática, que muitas vezes é apresentada perfeita - são mantidas na forma de dicionário, para permitir ao leitor acompanhar a história. Por exemplo, temos Nico, amigo de Chico, falando "esperei que você mesmo adivinhasse as coisas e fizesse o ensino perciso" (SILVEIRA, 1962, p. 134). Mesmo em uma leitura rápida é evidente que "perciso" significa "preciso", não taxando assim o leitor; enquanto uma frase puramente ortográfica poderia tornar-se confusa demais, arrastando a história e prejudicando o seu dinamismo (por exemplo, se todos os diálogos das personagens fossem como "’Perei ocê divinhá as coisa i fazê u insinu percisu").

Embora a maioria dos contos nos dois livros seguintes de Silveira, Nas serras e nas furnas (1931) e Mixuangos (1937), mantenha o mesmo estilo de Os caboclos, no primeiro há "Um magrinho" e "Perto do fogo" e, no segundo, "De duas cores", contos em que o 
narrador culto onisciente aparece de forma breve; a quase totalidade deles é tomada pelo discurso direto das personagens. Isso seria desenvolvido plenamente em Lereias (1945, póstumo), em que os narradores são os próprios habitantes do sertão, contando causos para o leitor, mantendo a transcrição ortográfica durante toda a história. Vejamos o início de um dos contos, "Mau costume":

- A mulher, p'ra ser completa, há de mentir, nem que seje só em certos momentos. Mulher que fala sempre a verdade inté é um perigo, pensando bem: arrepare no que sucedeu p'r'a coitada da Cotinha, casada c'o Quim da Serra, e veja se não tenho rezão neste meu dizer. (SILVEIRA, 2007a, p. 81).

Essa obra pode ser tomada como o ápice de todo o trabalho que esse descendente de bandeirantes desenvolveu ao longo de mais de quatro décadas de escrita. O subtítulo do livro bem resume o que foi buscado alcançar: "historias contadas por eles mesmos".

Mas, voltando alguns anos, encontramos na obra de Silveira um exemplo ímpar da união entre o culto e o dialetal: "Seo doutor". Este conto é inédito em livro, mas foi publicado em um jornal carioca em 1896. Algo incomum no estilo híbrido, Silveira utiliza um narrador em terceira pessoa:

Por este teor e forma, foram levando a conversa os diabos dos caboclos. Deu-lhes notícia o Baltazar, o mais arteiro sujeiro que o céu cobre, e criticou-a a seu bel prazer: e desde que ele puxara a fieira, os demais agarraram direito no diz-que-diz-que. Entrecontaram-se façanhas de arrepiar os cabelos [...] Tudo Ihes veio à retentiva, aumentado por ûa memória que sofria os calores da imaginação: que o menino, em resumo, não era tão ruim peça como eles queriam, lá isso não era, decerto... (SILVEIRA, 2007b, p. 95). 
Seguindo algo similar ao que Candido (2002, p.92) chamaria de "estilo castiço registrado segundo as convenções da norma culta", ao se referir a Simões Lopes Neto, Silveira, ao contrário de seus outros contos, apresenta discursos diretos sem a busca pela transcrição ortográfica. Vejamos o diálogo entre dois sertanejos:

- Pois você, Isa, ainda não se esqueceu do Valdóro? Não pense mais nele: fazendo das prateleiras de riba não a de ser pra nós, caipiras do mato. Largue mão disso!

- Mas o que hei de fazer [...] se o amor que tenho por ele a modos que cresce cada vez mais com a ausência? Eu quero esquecerme: eu quero, mas não posso! (SILVEIRA, 2007b, p. 101).

Nota-se o nome da personagem sobre a qual estão conversando: era o apelido do autor.

\section{Conclusão}

A literatura regionalista percorreu um caminho que se iniciou em Bernardo Guimarães, ou mesmo em Basílio da Gama, buscando compreender e retratar o mundo interiorano. Vimos dois autores que, estando o gênero ainda em fase evolutiva, experimentaram mais de um estilo, buscando maneiras de retratar o mundo rural; de fato, essa é uma história muito rica: poderíamos explorar o primeiro exemplo de estilo híbrido no regionalismo, em "O gado do Valha-me-Deus", do livro Contos amazônicos, de Inglês de Sousa, lançado em 1893. Quem sabe poderíamos voltar até mais: até "A vingança de um recruta", um dos contos de uma obra menos conhecida de Visconde de Taunay, Narrativas militares, de $1878^{\mathrm{iii}}$. 
"Experimentação" nos parece ser a palavra mais adequada para compreender o que foi feito, com os autores lidando com conceitos e temas pela primeira vez, tendo pouca, ou nenhuma, referência prévia, do que tentar enxergar uma suposta intenção dos autores de se mostrarem superiores a outra raça ou classe social; razão pela qual Coelho Neto foi criticado por Candido e que, se não ajudou, também nada fez para evitar que o escritor fosse colocado às margens dos estudos da literatura brasileira - onde ele se encontra até hoje, ao nosso ver, de forma injustaiv .

Candido, em outras obras, também criticou Arinos e Silveira, tomando-os por autores menores, responsáveis apenas por uma literatura pitoresca (em Formação da literatura brasileira, "Literatura e cultura de 1900 e 1945" e "Notas de crítica literária Sagarana", para citar algumas). Essas críticas, porém, são feitas sem detalhamento; muitas vezes os nomes são apenas citados. Mas um estudo das obras dos dois escritores indica não lhes faltarem dedicação, curiosidade e respeito ao interior do país e seus habitantes, talento e originalidade. Ambos foram parte essencial da evolução que levou a Simões Lopes Neto e Lobato à geração de 30 e além.

Essa evolução talvez não tenha sido tomada em consideração a contento. Candido deu, em suas críticas, enorme valor ao modernismo, em detrimento do regionalismo, chegando a dizer sobre este, em seu artigo "Literatura e cultura de 1900 e 1945", que "caberia ao modernismo orientá-lo no rumo certo" (CANDIDO, 2014, p. 121).

Será? E se o rumo já estivesse traçado? Não são poucos os autores da geração de 30 e posteriores que admitiram a influência que tiveram dos pré-modernistas, que seguiram esses precursores que praticavam o mesmo gênero literário, que tratavam dos mesmos tipos humanos, dos mesmos problemas, ocorridos nos mesmos locais, usando as 
mesmas formas discursivas, e não uma vanguarda urbana. Vejamos uma argumentação nesse sentido:

Há pontos de contato mas pouca possibilidade de combinação entre modernistas e regionalistas nas décadas de 1920 e 30 [...] A historiografia, às vezes, sugere ter havido um amadurecimento conceitual e um aprimoramento estético no regionalismo em decorrência das lições modernistas. Entendemos, diversamente, que a ficção regionalista qualifica-se ao distanciar-se do modernismo. Os regionalistas podiam prescindir, como prescindiram, do caráter de ruptura e revolução linguística sugerido pelo vanguardismo. Em seu lugar, preferiram adotar a linha evolutiva da ficção realista, que, no momento, libertava-se dos dogmas do evolucionismo oitocentista em favor da rica renovação da sensibilidade política (SANTOS, 2011, p. 293).

Mesmo que houvesse uma ligação, não seria mais correto inverter a frase que outorga aos modernistas uma tutela àquilo que os precederam, e admitir que, na verdade, o regionalismo indicou o rumo ao modernismo? Dando um exemplo importante, Mário de Andrade e Oswald de Andrade afirmavam que Monteiro Lobato, regionalista, foi um dos primeiros modernistas - Lobato que, por sua vez, era um admirador de Valdomiro Silveira, de quem se dedicou a publicar em livro a obra, formada por contos que estavam destinados a sofrer a deterioração inevitável dos jornais.

Retornemos ao artigo de Candido que apresentamos no início. Tomando as duas formas narrativas conforme postas pelo crítico em "A literatura e a formação do homem", e também a escrita apenas em norma culta, temos que nenhuma delas é, por si só, salvoconduto ou prova de crime, nenhuma delas implica, por si só, soberba ou igualdade: um autor do mais alto calibre, Bernado Élis, criou clássicos utilizando a transcrição ortográfica. Nas mãos de Coelho Neto, abolicionista engajado, homem sinceramente preocupado com a sociedade, seria soberba? Sem contar que mesmo aquilo que Candido 
generaliza como sendo "o regionalismo de Coelho Neto" (CANDIDO, 2002, p.88) indica apenas uma parcela de suas obras regionalistas. O curto "Mandoví" e "Os velhos" são os únicos contos de Sertão (1896) que utilizam a transcrição ortográfica - e o último apenas para uma personagem secundária; o restante dos contos do livro segue a norma culta ${ }^{v}$.

Ao mesmo tempo, a forma híbrida, tão elogiada em Simões Lopes Neto e Guimarães Rosa, foi utilizada após a década de 30 por inúmeros autores hoje considerados menores, pois era algo em voga. Em suma: a forma do discurso, por si só, diz pouco. Talvez algo mais esteja envolvido? Não estaríamos diante do que Luís Augusto Fischer (2011, p. 49) chama de uma "militância modernista" de Candido?

Mas, perguntarão, essa suposta militância... Simões Lopes Neto, pré-modernista, não foi elogiado pelo crítico? E não apenas em "A literatura e a formação do homem", de 1972, mas também em textos posteriores, como Iniciação à literatura brasileira, de 1987, onde diz que o autor pelotense "soube manter tanto a dignidade do tema quanto a excelência do tratamento literário" (CANDIDO, 1999, p. 67)? Sim. Antes, porém, em Formação da literatura brasileira, de 1959, Lopes Neto era visto indiscriminadamente no mesmo grupo de Lobato, Silveira, Arinos e, quem diria, do próprio Coelho Neto. Todos esses autores tenderiam igualmente a:

[...] anular o aspecto humano, em benefício de um pitoresco que se estende também à fala e ao gesto, tratando o homem como peça de paisagem, envolvendo ambos no mesmo tom de exotismo. É uma verdadeira alienação do homem dentro da literatura, uma reificação da sua substância espiritual, até pô-la no mesmo pé que as árvores e os cavalos, para deleite estético do homem da cidade (CANDIDO, 2013, p. 528). 
Uma grande diferença entre o Lopes Neto de 1959 e o de 1972! O autor passou de reificar o ser humano, igualando-o a plantas e cavalos, a escrever o tema com dignidade e excelência. Mas vejamos como o próprio Candido explica isso. Questionado em 2006 por Marcelo Frizon Guadagnin, sobre a possibilidade de ter havido "fases" em sua carreira, em que houveram visões diferentes para se enxergar o sertão, o crítico respondeu:

Não sei se tem razão quanto a "fases" em minha maneira de encarar o regionalismo. Ao longo de uma vida tão espichada quanto a minha, deve haver mais contradições do que fases (CANDIDO, 2007, p. 127).

De fato, as obras de Lopes Neto não mudaram uma vírgula entre uma data e outra, o que nos leva a uma possibilidade: apenas a partir da década de 1970, Candido leu de fato o autor pelotense, seja por ter dedicado o devido tempo a isso, seja pelo encanto modernista ter esvanecido, seja por ambos. Uma leitura pormenorizada de outros autores também seria capaz de alterar as críticas em que todos eram colocados no mesmo saco?

Acreditamos que sim. O caminho trilhado pela literatura regionalista brasileira pode não ter sido um mar de rosas, e não negamos que podemos encontrar textos de qualidade mediana ou duvidosa nessa jornada - o que acontece em qualquer gênero, em qualquer época. Mas muitas obras trouxeram algo novo e de qualidade; observá-las com atenção nos mostrará enorme riqueza, e como elas foram fundamentais para o que surgiu depois - digamos, para manter a mesma toada de Candido, quando a literatura que retrata o homem do interior alcançou sua maturidade. O importante é evitar, ao jogar a água suja fora, jogar também a criança. 


\section{Referências}

ARINOS, Afonso. Contos. São Paulo: Martins Fontes, 2006.

Nacionalização da arte (parecer de um curioso). In: GIL, Fernando C. Ensaios sobre a formação do romance brasileiro. Curitiba: UFPR, 2014, p. 321-328.

CANDIDO, Antonio. Iniciação à Literatura Brasileira. 3. ed. São Paulo: Humanitas, 1999. A literatura e a formação do homem. In: Textos de intervenção. São

Paulo: 34, 2002. p. 77-92.

Formação da literatura brasileira: momentos decisivos. 14. ed. Rio de Janeiro:

Ouro sobre Azul, 2013.

Literatura e cultura de 1900 e 1945. In: . Literatura e sociedade. 13. ed.

Rio de Janeiro: Ouro sobre Azul. 2014. p. 117-145.

FISCHER, Luis Augusto. A formação vista do sertão. Revista Brasileira de Literatura Comparada. Rio de Janeiro: Abralic, v. 13, n. 18, 2011, p. 41-72.

FREDERICO, Enid Yatsuda. Introdução. In: SILVEIRA, Valdomiro. Leréias. São Paulo: WMF Martins Fontes, 2007, p. ix-xxxviii.

GIL, Fernando C. O conto rural entre dois séculos: notas sobre algumas de suas transformações. In: O eixo e a roda. Belo Horizonte: UFMG, v. 25, n. 2, 2016, p. 27-46.

GUADAGNIN, Marcelo Frizon. O regionalismo na literatura brasileira: o diagnóstico de Antônio Cândido. 127f. Dissertação (Mestrado em Literatura) - Instituto de Letras, UFRGS, São Paulo, 2007.

SANTOS, Pedro Brum. Literatura e intervenção: romance histórico no Brasil. Floema. Vitória da Conquista: UESB, ano VII, n. 9, 2011, p. 283-303.

SILVEIRA, Valdomiro. Os caboclos. 3. ed. Rio de Janeiro: Civilização Brasileira, 1962. Leréias. São Paulo: WMF Martins Fontes, 2007. Mucufos. In: BARBOSA, Alexandre de Oliveira. Edição anotada de Mucufos, coletânea de contos inédita de Valdomiro Silveira. Dissertação (Mestrado em Literatura) Faculdade de Filosofia, Letras e Ciências Humanas, USP, São Paulo, 2007b, p. 42-232. 
TAUNAY, Visconde de. Advertência de Juca, o tropeiro. In: GIL, Fernando C. Ensaios sobre a formação do romance brasileiro. Curitiba: UFPR, 2014, p. 287.

\section{Recebido em 23 de maio de 2019.}

Aceite em 25 de junho de 2019.

\footnotetext{
i No artigo, Candido se refere ao estilo como seguindo uma "notação fonética", mas usaremos o termo "ortográfica".

ii O conto "Praga", de Coelho Neto, antecedeu ambos, tendo sido publicado pela primeira vez em 1890. Sua obra Sertão, da qual o conto veio a fazer parte, é de 1896.
}

iii Embora seja uma história militar passada durante a Guerra do Paraguai, o narrador e recruta do título, Tonico, é um roceiro de Itapororocas; é lá que se passam os primeiros capítulos da história, antes de a personagem se afastar de sua família e se unir aos voluntários.

iv Um artigo recente, que valoriza de maneira apropriada o autor de Rei negro, é "No trivial da ideia: o rural e o urbano no conto brasileiro na Primeira República", de Luís Bueno.

v Coelho Neto voltou a utilizar a transcrição ortográfica em alguns contos de Banzo (1913), e também no romance Rei negro (1914). 